\title{
Stereotyping as a Barrier in Intercultural Marketing: An Analysis of Public Online Comments on Dolce \& Gabbana's Incident in China
}

\author{
Wang Weichao, Wu Xiaoya* \\ Guangzhou, China \\ Email address: \\ jasonwangw@163.com (Wang Weichao),1364731118@qq.com (Wu Xiaoya) \\ ${ }^{*}$ Corresponding author
}

School of English for International Business, Center of Business Culture and Philosophy of Culture, Guangdong University of Foreign Studies,

\section{To cite this article:}

Wang Weichao, Wu Xiaoya. Stereotyping as a Barrier in Intercultural Marketing: An Analysis of Public Online Comments on Dolce \& Gabbana's Incident in China. International Journal of Literature and Arts. Special Issue: Humanity and Science: China's Intercultural Communication with the Outside World in the New Era. Vol. 8, No. 2, 2020, pp. 70-80. doi: 10.11648/j.ijla.20200802.16

Received: February 27, 2020; Accepted: March 16, 2020; Published: March 31, 2020

\begin{abstract}
This study investigates online comments on major social platforms following Dolce \& Gabbana (D \& G)'s promotional video Eating with Chopsticks in 2018 and the apology video released afterwards. By employing self-reference criterion (Browne, 2013), crisis communication and image restoration (Mair, Ritchie \& Walters, 2016), it first analyzes D \& G's stereotypes of the Chinese in the promotional video, then it further examines the cultural stereotypes and relative crisis communication strategies adopted by D \& G. It is found that D\&G's stereotype of the Chinese people can be reflected in the slanted eyes of the Chinese model, the background of the video and the comparison of chopsticks to small sticks. The Chinese people's stereotype of $D \& G$ can be indicated in the reaction to the promotional video as well as cultural misunderstanding in the crisis communication. It is thus argued that in designing promotional materials and managing crisis, international marketers need to be aware of various cultural stereotypes and take the cultural values of local consumers into full consideration, and such principles as empathy, mutual respect and mutual understanding need to be at international marketers' top priority. The purpose is to shed some light on intercultural marketing design and crisis communication for international corporations.
\end{abstract}

Keywords: Self-reference Criterion, Stereotype, Intercultural Marketing, Crisis Communication, Empathy

\section{Introduction}

With the development of multicultural enterprises, intercultural marketing has been playing an increasingly important role. Despite its increasing importance, problems still exist in many aspects. Stereotyping with over-generalization and over-simplification would always hinder intercultural marketing. Problems have been amply demonstrated in the case of Dolce \& Gabbanna (D \& G) in China in 2018 where the company's promotional video and responses led to a loss of more than RMB10 million Yuan ${ }^{1}$. Stereotype is a psychological concept first proposed by Walter Lippmann in his book Public Opinion in 1922, which refers to the fixed impression of a group that is difficult to change

1 http://www.ql1d.com/news/show/id/9473333.html. based on social classification according to gender, race, age or occupation [1]. Many studies investigate the impact of stereotype on intercultural marketing [2, 3]. For example, numerous global brands adopt Chinese elements in advertising as a localized adaptation strategy. The stereotype consistency of Chinese elements in advertising has a positive effect on intercultural marketing. Recently, various studies [4-6] have attempted to investigate stereotyping in intercultural communication by experimental analysis with Stereotype Content Model (SCM) to predict stereotype content in different contexts about a variety of groups. Therefore, it is necessary to conduct a study on stereotyping in intercultural communication. In fact, case analysis can provide "an intensive, holistic description and analysis of a single entity, phenomenon, or social unit" [7].

Many studies regard stereotype as a neutral concept. 
Nevertheless, this study emphasizes the negative concept of stereotype in intercultural marketing. The negative concept of stereotype stresses the characteristics of over-generalization, over-simplification and the ensuing communication obstacles; while the neutral one emphasizes its guiding significance in intercultural communication. For example, developing countries in Asia, Africa and the Middle East have suffered persistent challenges, such as poverty and political instability, which have resulted in ingrained stereotypical images [8]. Stereotypes towards destinations can be a serious barrier to the arrival of tourists and investors [9].

Moreover, this paper investigates (potential) consumers' attitudes towards the enterprise's possible underlying stereotyping of the Chinese. By collecting public comments on major online social platforms and with some follow-up interviews, stereotype can be more fully and comprehensively analyzed. D \& G's promotional video designed for its big show in China sparks heated discussion among the public. The ensuing comments made by the president of D \& G on the social platform aroused even greater anger, and many Chinese people considered the apology video issued by the two presidents as insincere. Through reviewing comments on this incident from different platforms, we find that there is not only stereotypical image towards Chinese people, but also stereotypical image held by Chinese people to D \& G. This paper focuses on the necessity of avoiding stereotype in localized advertising for both the organization and the public. Therefore, we delve into the negative concept of stereotype from both parties in intercultural marketing. In order to have more effective intercultural marketing and even intercultural communication at large, we attach importance to empathy and mutual understanding in intercultural communication. The following table offers a brief review of the development stages of D \& G's case.

Review of the case

Table 1. Timeline of $D \&$ \& 's incident in China.

Stage 1: D \& G
released a promotional
video
Stage 2: D \& G's
insulting words
provoke public anger
Stage 3: "being
hacked"
Stage 4: "The Great
Show" canceled
Stage 5: Apology
video released.

On November 17, 2018, D \& G, a luxury brand in Italy, released a promotional video Eating with Chopsticks to warm up The Great Show in Shanghai, China. The video depicts a Chinese woman, bedazzled in D \& G jewelry, using chopsticks to eat pizza, spaghetti, and an oversized pastry called cannoli. However, the video arouses controversy about racial discrimination. On November 21, 2018, at 11 a.m., the insulting words "country of shit" made by one of D \& G's designers are exposed online, which immediately provokes public anger. D \& G's insulting words provoke negative consequence including verbal and behavioral backlash against $\mathrm{D} \& \mathrm{G}$ from the common public and Chinese celebrities.

On November 21, 2018, at 1:52 p.m., D \& G later posts a statement that the accounts have been hacked but the statement arouses more criticism not only from the Chinese netizens but also from the Chinese official institutions.

D \& G's Shanghai show, scheduled for November 21, 2018, is canceled after many famous Chinese stars cease to attend the show. Then, at 4: 48 p.m., D \& G makes a response that it is not only unfortunate to them, but to those who work day and night for this.

On November 23, 2018, finally, almost three days after the promotional video is released, the two designers make an apology in a short video in Weibo. After 3 hours, they released it in Instagram, Facebook. However, the video causes a lot of controversy as well.

\section{Literature Review}

Stereotype represents a particular kind of categorization applied to groups, then projected to individuals associated with that particular group. Stereotypes, like categorizations, are a reality of our human nature but if left unchecked, they could lead cross-cultural managers into false assumptions about individuals and groups [10]. The study of stereotype focuses on psychology and sociology fields. In psychology, stereotype is defined as a cognitive schema and cognitive structure about a group's characteristics. Scholars verify the stable dimension of group description in Stereotype Content Model (SCM), and confirm the existence and formation mechanism of stereotype through a large number of empirical studies. Sociology, on the other hand, turns its perspective to the process of making and processing stereotypes, trying to determine the source of stereotypes from the media content and determine the significance of stereotypes. Sociologists regard stereotypes as cognitions of one social group about another social group or oversimplification [11], which constructs barriers in intercultural communication. Researchers have established that people stereotype others on a range of criteria including age, gender, ethnicity, nationality and even using sophisticated patterns of culture parameters such as the Hofstede (1980) type.

Most scholars tend to regard all stereotypes as negative, which leads to conflicts, clashes or culture barriers [12]. It is true that some categories (especially race, ethnicity) are harmful because people can discriminate 'others' [13]. On the other hand, stereotypes could be positive, serving as the first step to the contact between cultures. "Being a natural cognitive process of categorization, stereotyping is natural" [13].

Studies have explored the prevalence of stereotype in various contexts, such as media representations. For example, gender stereotypes have aroused great attention in the study of media discourse [14]. Studying the stereotypes of female and male celebrities may reflect the public's preconceptions of gender [14]. Recently, more and more research focus on the important role of stereotype representation in media from intercultural communication perspective. However, methodologically, case analysis and content analysis are often used to investigate the stereotype representation in different media platforms. Reactions from the mass audiences can make investigation more objective and comprehensive.

Studies have also explored the effects of stereotypes on marketing and business. Many scholars also investigate the impact of stereotype in business. Country stereotype, gender stereotype and age stereotype can exert great impact on marketing. For example, Spanish is less effective in advertising 
to Hispanic bilinguals than English is and English advertising language indeed outperforms advertising using Spanish [15]. In tourism industry, Eli Avraham [9] investigates nation branding and marketing strategies around the world that have been adopted to combat stereotype toward destinations. This examination makes use of quantitative and qualitative content analysis of seventy ads produced in forty-seven countries, including print ads, TV commercials and YouTube videos. What's more, an interplay between country stereotypes and perceived brand globalness/localness can exert great impact on brand preference [16]. In general, these researches about the effects of stereotype on marketing mainly use content analysis and experimental analysis methods. Investigation of negative effects of stereotype in achieving perceived brand localness by advertising in international marketing is still a nascent endeavor, and case analysis method and qualitative method are seldom used to conduct an analysis of stereotype.

Many studies concentrate on the stereotypes of Chinese people by interviewing Italian, Russian and Thailand students. The European and American tourists' stereotypes of China are studied by using the questionnaire survey and content analysis. The stereotypes of European and American visitors on China could be summarized as that China is a country with large population, long history, splendid culture, beautiful scenery, friendly people and rapidly developing economy [17]. Yu Xiya [18] analyzes stereotype on Chinese people based on the keywords in Aiqiyi. Gu Jie and Huang Ruohong [19] comprehensively analyze how the Italian mainstream media present the national image of China by both qualitative and quantitative methods. Numerous studies analyze the Chinese national image reflected in the early and later stage of Hollywood films. It often shows people with slender and small eyes or with strong closed eyeliner makeup [20]. Lin Xudan \& Chen Xiaoliang [21] and Wang Yuejie [22] investigate the stereotype of Americans towards China by questionnaire and the stereotypes of Thai students towards Chinese. "Vulgar" and "noisy" have become the main negative stereotypes of Thai students towards Chinese people. However, most research about different cultural groups to Chinese people in intercultural communication is conducted through content analysis and experimental analysis. Methodologically, more research about stereotype content need to be conducted through case analysis. In addition, few researches investigate the negative stereotype of Chinese people in designing localized advertising in intercultural marketing.

In summary, stereotype in business field can influence international business and intercultural communication. Despite substantial stereotype research in the intercultural communication and marketing field, more work is needed to identify the detrimental effect of biased impressions in intercultural marketing. This paper focuses on the negative stereotype in intercultural marketing, especially country stereotype in the localized advertising designed by an international company-D \& G, and country stereotype from the Chinese public. From a practical perspective, it is also important for multinational organizations to address stereotype. We hold that the failure of intercultural marketing in D \& G's incident can be mainly ascribed to D \& G's stereotype of China. But Chinese people's stereotype of D \& $\mathrm{G}$ may also contribute to the unsuccessful result. It is necessary to adopt empathy and avoid stereotype in intercultural communication for both sides.

\section{Theoretical Framework}

\subsection{Perceived Brand Localness}

Perceived Brand Localness (PBL) is defined as the extent to which a brand is perceived as being produced with the use of local resources [23]. Perceived Brand Localness refers to the extent to which a brand is "being recognized as a local player and a symbol or icon of the local culture" [24]. PBL captures individuals' perceptions of the extent to which a brand is produced with the use of local resources [25]. Such brand enables consumers to express their identity because they adapt to local tastes and local preferences. Global brands have made physical market presence across multiple countries. These brands generate a significant part of their revenue outside their home market.

Discussions about PBL are more recent, following the rise of anti-globalization and protectionist sentiments of buyers who desire to support their local markets [26]. The "localness" aspect of a brand goes beyond availability and reach, and includes a connection to the local culture as a defining feature [27-29]. Scholars find that PBL can significantly affect buyer behavior [30]. Thus, PBL is defined as the extent to which a brand is perceived as being produced with the use of local resources [31]. Buyers weigh brands that are connected to their country more favorably than brands that are not [31]. Therefore, intercultural organizations make localized advertising strategy to achieve brand localness.

\subsection{Country-of-origin Stereotype}

A large number of research have demonstrated that country of origin stereotype can influence consumer preferences. Consumers would associate different countries and their people with different features. Therefore, they would perceive these products from these countries based on the features. Stereotype is an over-simplified belief about any social category [18]. For example, Japanese is generally stereotyped as hard-working and disciplined. We would assume that an individual coming from Japan has these qualities. Stereotype research has suggested that stereotype can be applied to impressions of individuals, group-level perceptions, or country-level perceptions. Stereotype of a brand's country-of-origin will transfer to the product impressions [31]. In the paper, D \& $G$ makes a localized promotional video for their Chinese public to adapt to Chinese culture. However, from the comments we collect, stereotype in the video fails to achieve the perceived brand localness.

\section{Method}

\subsection{Case Study}

This study examines the opinions from different 
stakeholders to reveal stereotype content by analyzing D \& G's case. Case study can provide "an intensive, holistic description and analysis of a single entity, phenomenon, or social unit" [7]. Case study is well suited for developing an in-depth, contextual and holistic understanding [32]. This study adopts a qualitative study based on case analysis to enrich the existing research.

\subsection{Triangulation}

Triangulation is to combine multiple research materials, researchers, research theories and research methods to analyze the same problem in the same research to obtain a comprehensive in-depth explanation of the research problem, and to improve the breadth, depth and dimension of the analysis [33]. In this paper, triangulation method can help examine opinions following D \& G's promotional video and D $\&$ G's responses more comprehensively. Social media provide a new platform that sheds light on how the public react to the video, and interviewing data help validate the underlying reasons for the responses.

\subsection{Content Analysis}

Content analysis is employed to explore the comments on D \& G's promotional video and responses. Public opinion towards D \& G is deduced from the public comments posted on official social media accounts from Weibo, Zhihu, WeChat, Facebook, Instagram, and YouTube. In order to collect data on these different platforms, we conduct a search of the keywords "D \& G's video and D \& G's response and apology". On Weibo and Instagram platforms, we find topics respectively related to the promotional video and the three types of responses, namely denial, victimage and apology in crisis communication. However, on Zhihu, Facebook and YouTube, although there are many comments related to the promotional video and the screenshot, few topics are separately related to the three types of responses by D \& G. Therefore, it is deemed necessary to isolate the attitudes related to the three types of responses from these comments. When coding public comments on the incident, we firstly identify to which each public comment is responding, and ignore irrelevant comments.

We also collect articles from WeChat accounts by conducting a search of the keywords " $D \&$ \&". It is also necessary for us to isolate attitudes to the promotional video and three types of responses respectively.

\subsection{Data Collection}

We collect attitudes from Chinese media platforms including Weibo, Zhihu as well as Instagram, Facebook and YouTube (a total of 775 pieces) to represent different stakeholders' perspectives. Additionally, we also collect articles from WeChat accounts and conduct semi-structured interviews with four university teachers and seven students of different majors. The four university teachers include two teachers from Guangdong University of Foreign Studies (one Chinese and one British) and two teachers from Hefei Normal
University. All the teachers teach Business English; the seven students include three boys and four girls at the average age of 24. Six students are graduate students among which there are one medical major, one psychological major, one political major and three English Majors. There is one undergraduate student specializing in law. Interview consists of two types including face-to-face interviews and online interviews. Weibo is "a Twitter-like microblogging service provided by Sina Corporation" [34]. Without the requirement of high level of knowledge and expression ability, its users cover a wide range of social strata [35]. WeChat's account can provide a new way of information dissemination for media and individuals. Facebook is a social network service in the United States and Instagram is a photo-sharing social application. YouTube is the largest video website in the world. On these platforms, we only analyze text messages but exclude content such as pictures, videos, and hyperlinks from analysis.

Table 2 shows the number of comments collected. Table 3 lists the categorization of the comments and the interviews on the promotional video and screenshot from the platforms.

Table 2. Number of comments collected.

\begin{tabular}{lllll}
\hline & $\begin{array}{l}\text { Promotional } \\
\text { video and } \\
\text { screenshots }\end{array}$ & denial & victimage & apology \\
\hline Weibo & 20 & 95 & 97 & 103 \\
Zhihu & 60 & 36 & 26 & 51 \\
Facebook & 13 & 12 & 1 & 8 \\
Instagram & 12 & 89 & 70 & 82 \\
YouTube & 11 & 24 & 4 & 54 \\
WeChat accounts & 7 articles 23 articles & & \\
Interview & 11 interviewers including 4 teachers and 7 students \\
\hline
\end{tabular}

\section{Results and Discussion}

\subsection{D \& G's Stereotype of Chinese People}

D \& G's stereotype of China can be unveiled from the promotional video and the insulting words. Firstly, on November 18, D \& G released a post on China social media platform Weibo to promote its upcoming runway show in Shanghai on November 21. A design meant to pay tribute to the country and its consumers have come under fire for trivializing China's centuries-old culture and depicting Chinese women in a stereotypical and even racist way. Some people made comments on this video, "I feel bad for the model", "I find it absolutely offensive", and "Such tasteless ads. Full of sexual innuendos and condescending remarks", "the tone is insulting. The tone sounds so much like he pities her for being in China." "You are showing an overly dressed individual who look stupid trying to eat Italian food with 'small stick shaped cutlery'." There are also positive comments towards this video: "I don't get why it is racist. Could someone please explain in a friendly manner?" "I don't see any racism content in this ad. Can someone explain to me?" From these comments, this video backfires because it receives rampant negative comments on racial discrimination, condescending attitude and offensive remarks.

Secondly, at 11 a.m. November 21, 2018, the insulting 
words "country of shit" made by one of D \& G's designers are exposed online. Many famous Chinese stars including Chen Kun, Zhang Ziyi, Wang Junkai and some models announce their non-attendance at D \& G's Shanghai show. They declare their stands in Chinese media Weibo. Chen Kun says, "I will not attend D \& G's show tonight." Zhang Ziyi declares, "Zhang Ziyi will not attend the D \& G show in Shanghai tonight. From now, Ms. Zhang and her team will not purchase or use any D \& G products." Wang Junkai, "It is no doubt that you are the best, my country." Li Bingbing, "I love my country." Chinese netizens also express their anger, "We can never forgive the words 'country of shit'. Please get out of China". "Get your shit cloths out of China." In summary, D \& G's insulting words provoke serious consequence including verbal and behavioral backlash against D \& G from the public and many celebrities in China.

Table 3 summarizes the key points about why this campaign advertising is viewed as racist and discriminatory by Chinese audiences and opinions to the insulting words are summarized according to comments collected from different platforms.

Table 3. Categorization of opinions to the video and screenshots.

\begin{tabular}{|c|c|c|}
\hline D \& G's stereotype aout China & $\begin{array}{l}\text { Promotional video } \\
\text { Insulting words in screen shot }\end{array}$ & $\begin{array}{l}\text { The image of Oriental women with slanted eyes } \\
\text { Voiceover: imitating Chinese people's pronunciation } \\
\text { Voiceover: inductive tone to the Chinese model } \\
\text { Compare chopsticks to small sticks } \\
\text { Outdated background of the video } \\
\text { Insulting words- Eurocentrism } \\
\text { Insulting Chinese as racist }\end{array}$ \\
\hline
\end{tabular}

\subsubsection{Slanted Eyes of the Model}

The look of this Asian model - tiny eyes and childish smile - is a typical oriental type understood in the Western culture, which casts a western idea of a Chinese girl with slanted eyes, dressed in very expensive D \& G. A WeChat account comments, "It is the typical oriental sentiment imagined by westerners, not the Chinese image we are familiar with at all. The emphasis on 'slanted eyes' has been explicitly identified as 'racial stereotypes'." Another WeChat user says, "There's actually a word in English called 'Chink'. The word is extremely popular in the English-speaking world, and its origin is from an early foreign impression of the Chinese: slanted eyes of 45 degrees." "Chink" is an ethnic insulting word to refer to Chinese or East Asians. It may come from the pronunciation "please" and "Qing dynasty", the original character is only slightly different from "China", or it refers to small, slanted eyes. Therefore, slanted eyes depicted in the ad stirs up uproar among Chinese people.

\subsubsection{The Background of the Video}

Most of the Chinese cultural symbols and elements like lanterns and couplets that appeared in the messy background of the video, according to a Weibo user, are outdated and stereotypical. A Zhihu user says, "D \& G's understanding of China is still based on the imagination of the last century. The material seems to be from the last century, full of stereotypes of China in the 1980s and 1990s." Chinese people think that from the background of outdated folk and messy decoration as well as the "rigid" modeling, the brand presents an old, outdated stereotype of China. A WeChat user says, "With simple utensils and dim lights in the video, China, an ancient Oriental country with 5,000 years of civilization, has long been rejuvenated. Today, Chinese culture is increasingly diversified and globalized, and it changes with each passing day from content to style. However, D\& G's promotional video still focuses on the backwardness and conservatism of China." A Zhihu user also mentions the photos D \& G taken for Chinese people in 2017 to point out D \& G's intention to dwarfing China with depiction of conservatism and backwardness of China. "The shooting perspective does reveal some stereotypes of the east in the Western world with contrast between a Western, commercial and civilized beauty and a drawing of backward Chinese," the user says.

\subsubsection{Compare Chopsticks to Small-Sticks}

In the promotional video, the actress takes three kinds of Italian foods with chopsticks. In the verbal manner, D \& G compares chopsticks to small sticks. The subtitle refers to chopsticks as a "small-stick" tool while refers to Italian food as great and tasty, which makes many people feel the brand is arrogant. Criticisms to this behavior are listed in the following.

An article about D \& G's video says, "In the advertisements, the voiceover refers to chopsticks as 'small sticks' and 'pliers' many times. This would not be a problem if the advertisements are targeting Western audience as those words give a rough illustration of what chopsticks look like. Nevertheless, in this context, the advertisements cater to Chinese people and it is nonsensical to compare their civilized utensils to some random "small sticks"'. A WeChat account says, "The words 'little sticks' have been used many times to describe chopsticks which represent traditional Chinese culture. D \& G reduces chopsticks to "cutlery in the shape of small sticks' to highlight the superiority of Italian cuisine. Is this not the invasion of the strong Western culture to the weak Eastern culture? Italian food is often described in positive term like 'Great', while Chinese chopsticks are described in negative term like 'small'." Chinese food is inferior to Italian food because of the use of great "great pie" to describe Italian pizza.

In addition, some Chinese people think that $D \& G$ is offending Chinese civilization-chopsticks. A Zhihu user expresses the opinion: "It is no problem that she eats spaghetti with chopsticks, but the serious problem is that she holds chopsticks in the way she holds knife and fork. We know that on international occasions, if you do not understand the etiquette and customs of the other side, you should never act 
according to the customs of your own country, which would be a great offense. For example, when a Chinese person is kissed on the cheek, he has to jump on his feet. So, isn't it an insult to use chopsticks in a Western way?"

Unfortunately, D \& G interprets and expresses the symbol of "chopsticks" from its own life experience and cultural standpoint. Despite the fact that Western food is historically associated with a superior social status and luxurious lifestyle in China, putting the two cultures in such a contrasting way alienates and irritates many Chinese people. Nevertheless, growing up in a high-context culture, Chinese people are better at understanding symbols, non-verbal communication and indirect expressions than Westerners [36].

\subsubsection{The Condescending Voiceover}

In the promotional video, as the model eats Italian foods, the voiceover starts to mansplain to the Chinese model how to eat the "great spaghetti" with chopsticks. People criticize this behavior from two aspects including the imitating the pronunciation of Chinese people and inductive tone to instruct the Chinese model.

A Zhihu user says, "The brand names are pronounced oddly, as if they are mimicking Chinese pronunciation habits because many people don't know how to pronounce Dolce \& Gabbana in Italian. In contrast, this is not the case in other countries." An article says, "The stereotypical Chinese accent is indicated in this video. When the voiceover is saying words like 'Dolce \& Gabbana' and 'Bravissimo', the forced Chinese accent makes a lot of people shudder. While normal practice in the industry would be either to pronounce words correctly or to translate the foreign words into the local language, mimicking the accent of the target local audience is certainly not an option."

Another WeChat account criticizes the voiceover, "The model is instructed to insert a chopstick into the cannolo and put it into her mouth by a condescending voiceover. The model then presents silly movements and exaggerated expressions. It is easy to make people who do not know the situation in other countries think that 'Asian women turned out to be such stupid and ugly creatures' with arrogant and superior tone." "This kind of teaching video is equivalent to a parent teaching his son and to look at barbarians from a height." "This is a Western stereotype and discrimination against Asian women, depicting them as stupid and ignorant." "It is difficult to figure out why D \& G incorporates those exaggerated non-verbal expressions into the videos, especially when considering that the Chinese people, born in a high context culture, are sensitive to these."

\subsubsection{Insulting Chinese People in the Screenshot}

According to a screenshot exposed, Stefano Gabbana, a designer of $D \& G$ said that he does not think the video entails discrimination against Chinese people and he blames that deleting video was very stupid. Consequently, he describes China as "shit" and "ignorance dirty stench gangs". What's more, he claims that Chinese is more racist because Chinese people eat dogs. While Chinese people ascribe this verbal behavior to Occidentalism mindset, which denotes an excessively distorted sense of superiority at the theoretical cultural level and it ignores the reality and characteristics of the development of countries so that in the process of cultural interaction, it unconsciously puts its own culture above other cultures.

\subsection{Chinese People's Stereotype of D\& G}

With the promotional video released and the screenshot exposed, D \& G makes three types of responses to Chinese people as summarized in the timeline of the incident. Nevertheless, after reviewing the comments to these three types of responses separately, we find that the responses are not accepted by the Chinese people. We find extreme expressions and behaviors from online comments such as dirty and insulting words like "get out of China", "son of a bitch" etc., and even some extreme behaviors like burning D \& G clothes. Therefore, we hold that not only $D \& G$ have stereotype of China, but Chinese people have stereotype of D \& G.

Following the release of "being hacked" response, some netizens say, "This is an outdated excuse. I don't believe it." "It is too stupid for them to use this excuse". "They insult our intelligence. They insult us again." At the same time, the communist youth league's account releases a statement in Weibo that "We welcome foreign enterprises to invest and do business in China, and foreign enterprises operating in China should respect China and the Chinese people. This is also the minimum requirement for any enterprise to invest in other countries and carry out cooperation." "Being hacked" response induces more criticism not only from the Chinese netizens but also from the Chinese official institutions.

D \& G's Shanghai show, scheduled for November 21, 2018 , is canceled after many famous Chinese stars cease to attend the show. D \& G prepares an enormous show covering 18700 square meters with 40 stars, 360 models, 1600 furnishings and equipment, 500 pieces of clothes, totaling 8 million $\mathrm{RMB}^{2}$. Then, at 4: 48 p.m., D \& G responds that it is not only unfortunate to them, but to those work day and night for this event. In the evening, Chinese stars including Dilireba and Wang Junkai announce their termination of the agreement with D \& G. After models and stars issue boycott statements, eight mainstream e-commerce platforms operating luxury business in China remove all products related to $D \& G$ off the shelves including three major e-commerce giants T-mall, Jingdong and Suning e-commerce as well as Netease koala, luxury e-commerce Siku, Vipshop, Store 1 and overseas shopping platforms.

The apology video causes a lot of controversy as well.

The following part would analyze the latter stereotype from the comments to the three types of responses. Chinese people's stereotype can be attributed to self-reference criterion. Self-reference criterion refers to making decisions based on one's cultural values, experience and knowledge. In cross-cultural business activities, self-reference criteria are often manifested as an ethnocentric tendency, believing that

2 http://opinion.people.com.cn/n1/2018/1123/c1003-30418731.html. 
the values of the culture are the best or preferred about how to do things and viewing each other accordingly [37].

As demonstrated in table 5 by the categorization in Table 4 , the crisis communication, namely denial, victimage, apology adopted by D \& G engender different public responses. Table 4 offers an account of the opinions to D \& G's responses, and table 5 categorizes the opinions to D \& G's responses.

Table 4. Opinions to $D \& G$ 's responses.

\begin{tabular}{|c|c|c|c|}
\hline $\begin{array}{l}\text { Opinions } \\
\text { from different } \\
\text { platforms }\end{array}$ & $\begin{array}{l}\text { Denial } \\
\text { Dirty words to vent emotions } \\
\text { Being outdated } \\
\text { Making responses for money } \\
\text { Proving you being hacked } \\
\text { Insulting Chinese intelligence } \\
\text { Like a coward } \\
\text { "shuaiguo", Shirking responsibility } \\
\text { "Habitual offenders" } \\
\text { National dignity is inviolable } \\
\text { Insincerity and untimeliness } \\
\text { Evading explaining the video } \\
\text { Stopping buying D \& G products }\end{array}$ & $\begin{array}{l}\text { Victimage } \\
\text { Dirty words to vent emotions } \\
\text { No apology words } \\
\text { It shows only regret and unfortunate and implies } \\
\text { that he is the victim who is wronged } \\
\text { Arrogant attitude, superiority, big show cancel is } \\
\text { the loss of the Chinese } \\
\text { Response for money } \\
\text { Apology in English is not for Chinese } \\
\text { When you scold DG, you don't see how you } \\
\text { discriminate against black people and homosexuals }\end{array}$ & $\begin{array}{l}\text { Apology } \\
\text { Dirty words to vent emotions } \\
\text { Apologizing for money } \\
\text { Evading the crucial points, blaming } \\
\text { cultural differences. } \\
\text { External performance (dressing, body } \\
\text { movement, etc.) shows insincerity } \\
\text { It's too late. } \\
\text { Apology video is not released in Instagram } \\
\text { Don't understand Chinese culture }\end{array}$ \\
\hline
\end{tabular}

Table 5. Categorization of opinions to $D \&$ \& 's responses.

\begin{tabular}{|c|c|c|}
\hline \multirow{7}{*}{$\begin{array}{l}\text { Chinese people's } \\
\text { stereotype }\end{array}$} & Denial response & $\begin{array}{l}\text { Insulting Chinese intelligence-superiority } \\
\text { "shuaiguo", Shirking responsibility } \\
\text { Evading explaining the video }\end{array}$ \\
\hline & Victimage response & $\begin{array}{l}\text { Arrogant attitude, superiority, big show cancel is the loss of the Chinese } \\
\text { Response for money }\end{array}$ \\
\hline & & Apologizing for money \\
\hline & & Evading the crucial points, blaming cultural differences. \\
\hline & Apology response & External performance (dressing, body movement, etc.) shows insincerity \\
\hline & & Apology video is not released in Instagram \\
\hline & & Don't understand Chinese culture \\
\hline
\end{tabular}

The denial response is adopted to deal with the crisis of the insulting statements made by the two designers. Their statement is as follows:

"Our Instagram account has been hacked. So as the account of Stefano Gabbana. Our legal office is urgently investigating. We are very sorry for any distress caused by these unauthorized posts. We have nothing but respect for China and the people of China."

\subsection{1. "Being Hacked" Indicates "Superiority"}

By analyzing the comments, some people say, "It is stupid to use this strategy", "They are insulting our intelligence again", and "This is a convenient strategy". D \& G's denial strategy presents a sense of superiority because this strategy is effortless and convenient. As a teacher says, "We need eggs but we squeeze the living space of hens because we look down upon hens. D \& G also looks down upon Chinese people because it is so easy for them to make money from Chinese people. They are reluctant to spend time and efforts in apologizing and explaining and they choose a simple and easy response." In the sense of stereotype, Chinese people think their denial indicates superiority.

\subsection{2. "Being Hacked" Indicates a Lack of Responsibility}

"Shuaiguo" in Chinese means to shirk responsibility. However, in the Chinese context, undertaking responsibility ranks high. "Coward" is also a negative word to describe D \&
G's behavior. Some say, "D \& G has the courage to make insulting words but dares not to admit it and shoulder responsibility." We should attach importance to responsibility in dealing with a crisis in the Chinese context. An account says, "No matter whether D \& G has made this statement or not, it should apologize because in the previous video, everyone has suspected that you have this intention, so you should explain it carefully and apologize." Chinese people admire and appreciate those who have the courage to take responsibility for mistakes while Westerners think admission of guilt can mark the beginning of legal and reputational difficulties to come [38]. In Chinese culture, only by being brave enough to take responsibility and showing full honesty to the public can we finally gain public sympathy, understanding, trust and support. In Italian culture, D \& G refuses to avoid legal and reputational difficulty. Therefore, we can conclude that Chinese people judge D \& G's denial from Chinese own culture.

\subsubsection{Over-reaction}

There are also positive opinions towards the insulting words made by D \& G. In the YouTube clip, a Chinese woman says, "They have no choice but to say 'being hacked' because apology means the insulting words were purposeful." An American man says in a video on YouTube, "D \& G may have some quarrel with the Vietnam girl (the girl who releases the screenshot). They have a private conversation but the girl is 
angry in the quarrel so she exposes the screenshot with insulting words. The designer is angry, too. Every angry man would do something insane. It is understandable. However, most Chinese people decide not to buy their products. It is kind of overreaction because it is the designer who says something wrong. This product has good quality. We cannot deny its good quality and design of this brand with decades of years' history just because of the insulting words made by the designer in an angry mood."

It is clear that some American people think Chinese people overreact to the insulting words and Chinese people confuse products with the designers. However, the American man thinks there is a separation between designers and products because we buy products due to the good quality. When operating in a comparatively collectivistic culture like China, a company can never excise its relation with top executives. In this case, it is the designer and founder CEO of D \& G made those insulting words. The cleave point between designer and products may not be readily available. It also has something to do with power distance. With comparatively higher power distance in China, the designer and CEO represent the image of the company. As an account says, "It is fine if the average shop assistant has these problems, but D \& G's biggest problem is that it is the direct leader, the top designer who makes those insulting words, which also makes crisis communication very troublesome." According to self-reference criterion, Chinese people take D \& G's insulting words seriously because of their high power distance and collectivistic context, so some people make dirty words and burn D \& G's clothes to vent their emotion but in the D \& G's eyes, there is a separation between the brand and the designer.

Victimage strategy is adopted to deal with the non-attendance of Chinese stars in the fashion show.

They said, "Our dream was to bring to Shanghai a tribute event dedicated to China which tells us history and vision. It was not simply a fashion show, but something that we created especially with love and passion for China and all the people around the world who loves Dolce \& Gabbana. What happened today was very unfortunate not only for us, but also for all the people who worked day and night to bring this event to life. From the bottom of our hearts, we would like to express our gratitude to our friends and guests."

We isolated comments related to the victimage strategy from topics about $D \& G$ in these social media platforms by searching for key words like "D \& G's show cancelled", "D \& G unfortunate".

\subsubsection{Victimage Indicates Arrogance and Superiority}

In the interview, a university teacher carefully analyzes the words, "This statement is like what God says to his people. The words 'bring', 'tribute', 'tell our history and vision' can indicate this. For example, the God would say 'I will bring you light, I will bring you food, and I will bring you life'. They say 'it' is unfortunate and then the workers, but they do not mention Chinese people. They express their gratitude to friends and customers but not to Chinese people." He says, "D $\& \mathrm{G}$ thinks that you Chinese people are not my friends or my clients. What is your qualification to judge and let us apologize?" The teacher points out the president's arrogant attitude between his words in the statement. For most Chinese people, D \& G's statement indicates that the show is a charity to Chinese people and it is such a pity for Chinese people missing the show. D \& G's mistake lies in overlooking China from the very beginning. In his mind, Chinese people should look up to D \& G. While for D \& G, they prepare for a long time with great effort and money for this great show and make a promotional video to cater to Chinese people. Nevertheless, the boycott incurs huge losses for D \& G. As a luxury brand, they present themselves as unfortunate victims.

\subsubsection{Victimage Indicates a Self-oriented/Self-centered Mindset}

"Self-centered" means being limited to or caring only about oneself and one's own needs. As a teacher says, "The statement shows a complaint tone with the word 'unfortunate' tour Chinese people's overreaction leads to their loss of money. D \& $\mathrm{G}$ do not mention the damage brought to Chinese people." A Zhihu user says, "The statement is more likely to show that D \& $\mathrm{G}$ is seeking international sympathy and support for itself, while ignoring the harm it has done to Chinese consumers." A WeChat account says, "Organizations should concentrate on public interest and public sentiment in crisis communication." Liu Run, former director of Microsoft, says, "The essence of crisis communication is public sentiment management." In many cases, the public is very concerned about whether enterprises care about their feelings. Therefore, enterprises should think from the perspective of the public and treat the public as victims. However, when we have an interview with a British teacher, he says, "For D \& G, China is more powerful than the company. Chinese public's reaction leads to the cancellation of the show. Therefore, they think they are the victim." From D \& G's standpoint, according to statistics, D \& $\mathrm{G}$ suffered a huge loss due to the boycott from Chinese people and the cancellation of the show. From Chinese people's standpoint, the insulting words offend national dignity and hurt their feelings. Even if the public has a certain responsibility in the crisis, the enterprise should not place the blame on the public; otherwise, it will only deepen the contradiction and cause the public's antipathy, which is not conducive to problem resolution. Therefore, intercultural crisis communication requires empathy and a public-oriented mindset.

D \& G finally releases their apology video six days after the original promotional video is released.

They said,

"Over the past few days, we have been seriously reflecting that our love for China is as strong as ever. Countless visits have deepened our love for Chinese culture. Of course, we still have a lot to learn. We must apologize for the mistake we made in our previous statement. We will never forget this experience and lesson, and this kind of thing will never happen again. At the same time, we will do our best to better understand and respect Chinese culture. Finally, we ask for your forgiveness sincerely. I am sorry. We will never forget this experience and lesson, and it will never happen again. At the same time, we 
will do our best to better understand and respect Chinese culture. Finally, we ask for your forgiveness sincerely. Sorry (in Chinese)."

There are various comments concerning this apology video on Weibo, Zhihu accounts, Facebook, Instagram, YouTube and interviews. Criticism towards the video focused on many aspects. However, negative comments still far outweigh positive comments.

\subsubsection{The Content of Apology: Cultural Misunderstanding or Value}

D \& G blames their mistakes on cultural misunderstanding without mentioning the promotional video and insulting words. Instead of acknowledging the inappropriateness of his insulting remarks and propaganda video, D \& G uses the excuse of "our cultural misunderstanding". A WeChat account says, "He attributed the crisis to 'cultural misunderstanding', which is to explain the online debate caused by the previous promotional video, but he did not talk about the real trigger of the crisis, that is the insulting remarks, not to mention explaining the previous statement 'being hacked'."

$D \& G$ evades explaining the crucial part in the whole process about the insulting words by cultural misunderstanding. Some people express their opinion that D $\&$ G should reflect on themselves from their organization's value. As a Zhihu user says, "The core of crisis communication is attitude and responsibility. Value is the cornerstone of an enterprise at any time in a crisis." The Zhihu user offers a revised version for D \& G, "We do not fully consider the sensitivity of different cultures around the world and completely ignored the pride of Chinese people in their own nation and culture. While reviewing our creativity, we should also reexamine our values. Although the main founders of the company have emotional impulses in the social media conversation, the appearance of such comments also reflect our immature and unsound values, and our unclear understanding of the moral standards that we should embody as a global enterprise."

Enterprise values refer to the value orientation of enterprises and their employees, the basic beliefs and goals that enterprises advocate in the course of pursuing business success. Organizations need to constantly reflect on their cultural value especially in crisis communication.

\subsubsection{Apologizing for Money}

Many Chinese people think that D \& G is responding to stop losses in a timely manner. "It is not D \& G Loves China, but D \& G loves China's RMB," as many Weibo, Zhihu, WeChat, Instagram and YouTube users say. After the release of the promotional video and the boycott to D \& G, D \& G's market share in China is decreasing at a rapid speed, which is one typical disaster that multinational enterprises might bring themselves to with poor crisis communication.

\subsubsection{Manner of Apology: Nonverbal Behaviors}

Nonverbal behaviors play an important role in apology. Large amounts of comments refer to the insincerity in D \& G's apology video. A number of factors contribute to insincerity.
Many people point out that the two founders dress pajamas-like clothes in the video. For international practices, they should wear formal clothes when apologizing to show sincerity. Some people say, "They can't even recite the apology words with only 1 minute and 52 seconds! They always look at the teleprompter." A teacher points out the insincerity from gestures, "One of the designer makes a dismissive gesture when he says sorry." A student points out their insincerity because they release the video on Instagram, Facebook and YouTube three hours later. He says, "Maybe D $\& \mathrm{G}$ is afraid that others look down upon them as a flunkey of Chinese if they release the video on other platforms." Other online users say, "Maybe they want to maintain their image in the world so they are reluctant to release apology video on Instagram and other platforms." A Zhihu user even says, "We Chinese people would never sit down and apologize. And it is our culture to bow when apologize." When operating in a high-context culture with relatively large power distance like China, people are very sensitive to implicit information. It is desirable for them to understand Chinese culture about apology to indicate their sincerity. It is necessary for them to stand up and bow to apologize and pay attention to details like dressing code and implicit information. And they can try to apologize through a variety of network media channels to expand the impact of the apology statement.

What's more, sincerity cannot be achieved only by words. A teachers says, “Language doesn't make any sense. The key is to do something. The key is sincerity in apology. We can measure the sincerity from three indicators: time, efforts and money." D \& G claim that they respect Chinese culture. In intercultural crisis communication, organizations need to learn how to apologize by conforming to a country's culture. To further demonstrate their sincerity in Chinese context, they can donate money to run-down areas in China because money and efforts are indicators of their sincerity.

We can conclude that Chinese people criticize D \& G's apology as insincere based on Chinese culture. Therefore, empathy is important in intercultural marketing. The audience also have to be empathetic and understand the apology video from D \& G's culture.

\subsubsection{The Untimeliness of Apology}

The apology video is released on November 23, 2018, 6 days after the release of the promotional video. The apology has missed the best time of crisis communication. It is also criticized as being too late. A WeChat account points out that only when $D \& G$ products are off the shelves of all the domestic e-commerce platforms, D \& G starts panicking. The two founders' apology is so late that Chinese people believe that the apology is to stop the economic losses in the Chinese market. The untimeliness of the apology contributes to "a culture of being forced to apologize", which is mentioned by a German YouTube user. He thinks they are forced to apologize for money. A WeChat account says, "The response must be fast, and the "golden four hours" in crisis communication must be grasped. Once the brand loses the customer's heart, it is difficult to acquire again." 


\section{Conclusion}

Previous studies indicate that stereotype in advertising can exert great impact on intercultural marketing. In this paper, we achieve a thorough and comprehensive understanding of the stereotype from both sides. Specifically, we reveal D \& G's stereotype of Chinese people and Chinese people stereotype of $D \& G$ by collecting comments from major platforms. This case analysis can demonstrate clearly that stereotypes from both parties lead to the fallout of D \& G's intercultural marketing in China.

D \& G's stereotype of China is reflected from the slanted eyes of the model, comparing Chinese chopsticks to small sticks and the outdated background of the video, the condescending voiceover and the insulting words. Chinese self-reference is reflected from the attitudes toward D \& G's responses. For example, being hacked is an outdated response, but $D \& G$ is unwilling to take efforts to make other responses, which indicates their sense of superiority. Nevertheless, it is desirable for $D \& G$ to shoulder responsibility no matter whether they do anything wrong. Moreover, acting as a victim indicates their self-centeredness. Chinese people point out apologizing to money not to Chinese people and the nonverbal behaviors in the apology video from Chinese culture. These are Chinese people's stereotype of D \& G. It is safe to say that both sides' stereotype lead to the crisis.

By investigating D \& G's incident in China, this study emphasizes the importance of empathy in intercultural communication. D \& G's localized promotional video backfires because of its country stereotype of China and its responses receive negative comments due to Chinese people's stereotype of D \& G. Due to cultural differences, it is undeniable that cultural conflicts would arise in the intercultural communication. If we view something from the standpoint of the other part rather than solely from our own culture, misunderstanding and conflict can be minimized in intercultural communication. In a word, successful intercultural communication calls for empathy and the restraint of self-reference criterion.

\section{References}

[1] Lippmann, W, "Public Opinion,” New York: MacMillan, 1922. (references).

[2] He, J. X., Wu, Y., and Xie, R. Q (2014), Do Chinese Elements Matter? Consumer Evaluation on the Localized Adaption Strategy for Global Brand from the Perspective of Stereotype Consistency. Journal of East China Normal University (Humanities and Social Sciences), 46 (05): 131-145+182.

[3] Heberle, A. B and Carter, A. S. (2020), Young children's stereotype endorsement about people in poverty: Age and economic status effects. Children and Youth Services Review, 108.

[4] Guan, Y. J., Deng H., and Bond, M. H. (2010), Examining Stereotype Content Model in a Chinese context: Inter-group structural relations and Mainland Chinese's stereotypes towards Hong Kong Chinese. International Journal of
Intercultural Relations, 34 (4): 393-399.

[5] Tung, V. W. S., King, B. E. M, and Tse, S. (2020), The Tourist Stereotype Model: Positive and Negative Dimensions. Journal of Travel Research, 59 (1): 37-51.

[6] Racheal, A. R. and Zhang Y. B. (2013), Stereotypes of Chinese international students held by Americans? International Journal of Intercultural Relations, 37 (2): 202-211.

[7] Merriam, S. B., (1998), "Qualitative research and case study applications in education," San Francisco, CA: Jossey-Bass.

[8] Sharpley, R. (2017), Tourism marketing for developing countries: Battling stereotypes and crises in Asia, Africa and the Middle East. Tourism Management, 59: 108-109.

[9] Avraham, E (2018). Nation branding and marketing strategies for combatting tourism crises and stereotypes toward destinations. Journal of Business Research.

[10] Brent, R. and Worthley R., (2012), Individual characteristics as predictors of cultural intelligence development: The relevance of self-efficacy. International Journal of Intercultural Relations, 36 (1): 62-71.

[11] Moore, J. R. (2006), Shattering stereotypes: A lesson plan for improving student attitudes and behavior towards minority groups. The Social Studies, 35-39.

[12] Gu, J., (2009), "Theorizing about intercultural communication: Dynamic semiotic and memetic approach to intercultural communication (a commentary)," Intercultural Communication Research Beijing: Higher Education Press, pp. 109-115.

[13] Pinker, S., (2003) "Blank slate: The modern denial of human nature," New York, Penguin Books.

[14] Wang, H. C., (2009). Language and ideology: gender stereotypes of female and male artists in Taiwanese tabloids. Discourse \& Society, 20 (6): 747-774.

[15] Cecilia, M. O., Paul, W. and Jaccard, J. (2017). How Hispanic bilinguals' cultural stereotypes shape advertising persuasiveness. Journal of Business Research, 75: 29-36.

[16] Halkias, G., Davvetas, V. and Diamantopoulos, A (2016). The interplay between country stereotypes and perceived brand globalness/localness as drivers of brand preference. Journal of Business Research, 69 (9): 3621-3628.

[17] Wang, Y. D., Wu, J. F., Wu J., Wu, S. S (2015). European and American tourists' stereotypes on China. Journal of Arid Land Resources and Environment, 29 (06): 202-208.

[18] Yu, Y. X. (2019). An analysis of China's image from the perspective of foreigners. Youth Journalist, (29): 30-31.

[19] Gu, J. and Huang, R. H (2018). Beyond stereotypes: the image of China presented by Italian media--a case study of China related reports in the Corriere della Sera. (03): 106-110.

[20] Niu, L. (2019). Star Eyes: a stereotype that cannot be eradicated. Journal of Beijing Film Academy, (04): 95-104.

[21] Lin, X. D. and Chen, X. L. (2019). Stereotype and identity construction under the background of transnational education mobility: a case study of Chinese international students in the United States. Human Geography, 34 (03): 68-74. 
[22] Wang, Y. J. and Shan, Y. M. (2018). The Study on Thai International Students' Stereotypes about Chinese People. Youth Studies, (04): 84-93+96.

[23] Sichtmann, C., Davvetas, V., and Diamantopoulos, A (2019). The relational value of perceived brand globalness and localness, Journal of Business Research, 104: 597-613.

[24] Swoboda, B., Berg, B., Schramm-Klein, H., and Foscht, T (2013). The importance of retail brand equity and store accessibility for store loyalty in local competition. Journal of Retailing and Consumer Services, 20 (3): 251-262.

[25] Steenkamp, J.-B. E. M., De Jong, M. G. (2010). A global investigation into the constellation of consumer attitudes toward global and local products. Journal of Marketing, 74 (6): $18-40$.

[26] Dimofte, C. V., Johansson, J. K., and Ronkainen, I. A (2008). Cognitive and affective reactions of U.S. consumers to global brands. Journal of International Marketing, 16 (4): 113-135.

[27] Lim, K. and O'Cass, A (2001). Consumer brand classifications: An assessment of culture-of origin versus country-of-origin. The Journal of Product and Brand Management, 10 (2): 120 136.

[28] Swoboda, B., Pennemann, K., and Taube, M. (2012). The effects of perceived brand globalness and perceived brand localness in China: Empirical evidence on western, Asian, and domestic retailers. Journal of International Marketing, 20 (4): $72-95$.

[29] Davvetas, V., Diamantopoulos, A., and Halkias, G. (2016). Turning the tables: Building strong local brands to compete against global rivals. Proceedings annual conference of the European Marketing Academy.

[30] Balabanis, G. and Diamantopoulos, A. (2004). Domestic country bias, country-of-origin effects, and consumer ethnocentrism: A multidimensional unfolding approach. Journal of the Academy of Marketing Science, 32 (1): 80-95.
[31] Herz, M. F. and Diamantopoulos, D. (2013). Country-Specific Associations Made by Consumers: A Dual-Coding Theory Perspective. Journal of International Marketing, 21 (3): 95-121.

[32] Yin, R. K, "Case study research: Design and methods (4ed.)," Los Angeles, CA: Sage, 2009. (references).

[33] Sun, J. (2006). "Triangulation" as a combination of qualitative research and quantitative research: a review of international studies. Social Sciences in Nanjing, (10): 122-128.

[34] Yuan, E. J., Feng, M., and Danowski, J. A (2013). "Privacy" in semantic networks on Chinese social media: The case of Sina Weibo. Journal of Communication, 63: 1011-1031.

[35] Wang, Q. J., and Zhang, J (2017). The analysis of the characteristics of ontology, subject and transmission of Micro-Blog comments. Editorial Friend, (09): 59-62.

[36] Pae, J. H., Samiee, S., and Tai, S (2002). Global advertising strategy: the moderating role of brand familarity and execution style. International Marketing Review, 19 (2): 176-189.

[37] Zhao, Y. D. (2005). Research on the differences of values in cross-cultural business activities. Forum on Jiang $\mathrm{Su}$ Commerce.

[38] Tyler, L. (1997). Liability means never being able to say you're sorry: Corporate guilt, legal constraints, and defensiveness in corporate communication. Management Communication Quarterly, 11 (1): 51-73.

[39] Wang, L. (2007). On the Relevance of the Audience Stereotypes and the Advertisement Cultural Fake. Press Circles, (04): 129-130.

[40] Xie, L. (2013). On the role of cultural stereotype in intercultural communication. Journal of PLA University of Foreign Languages, 36 (02): 33-38.

[41] Živa K., Arslanagic-Kalajdzic, M., and Diamantopoulos, A. (2019). Stereotyping global brands: Is warmth more important than competence? Journal of Business Research, 104: 614-621. 